\title{
'All Your Chocolate Rain are Belonging to Us?': Viral Video, YouTube and the Dynamics of Participatory Culture
}

\section{Jean Burgess}

Marketers and media producers for the past several years have been racing to capture the marketing potential of both online social networks and user-created content. 'Viral marketing', for example, is the attempt to exploit the network effects of word-of-mouth and internet communication to induce a massive number of users to pass on 'marketing messages and brand information voluntarily.' 1 The related term 'viral video' has emerged to describe the phenomenon in which video clips become highly popular through rapid, user-led distribution via the internet. How, or whether, the 'bottom-up' dynamics of viral video can be mobilised for instrumental purposes - from marketing to political advertising - remains an open question. But 'viral video' could be much more than a banal marketing buzzword - in fact, interrogating it a bit more closely in the specific context of YouTube can help us cut through the hype and better understand some of the more complex characteristics of participatory popular culture online.

In popular usage, the term 'viral' (and the related internet 'meme') are of course very loosely applied biological metaphors, appropriated from various attempts to develop a science of cultural transmission based on evolutionary theory that have been unfolding for decades. The contested field of 'memetics' is the best-known, but by no means only, strand of this kind of 
thinking, which began with Richard Dawkins' proposal in The Selfish Gene of the 'meme' as the corresponding cultural unit to the biological gene. ${ }^{2}$ Similar to the scientific usage in meaning if not analytical precision, in contemporary popular usage an internet 'meme' is a faddish joke or practice (like a humorous way of captioning cat pictures) that becomes widely imitated. In this popular understanding, internet 'memes' do appear to spread and replicate 'virally' - that is, they appear to spread and mutate via distributed networks in ways that the original producers cannot determine and control.

But, in a step backward from the more participatory idea of the internet 'meme', very often the term 'viral video' is used to refer simply to those videos which are viewed by a large number of people, generally as a result of knowledge about the video being spread rapidly through the internet population via word-of-mouth. For example, Dan Ackerman Greenberg runs an 'astroturfing' company, employing covert strategies to turn apparently authentic (but actually commercial) videos 'viral'. In his now-notorious post on the technology business weblog Techrunch, Greenberg defines viral videos as 'videos that have travelled all around the internet and been posted on YouTube, MySpace, Google Video, Facebook, Digg, blogs, etc. - videos with millions and millions of views'. ${ }^{3}$ This focus on networked distribution resulting in 'millions and millions of views', while it makes sense to advertisers, is an oversimplification of the dynamics of online popular culture. In this chapter I propose an alternative view, one that emphasises the central role of cultural participation in the creation of cultural, social and economic value in participatory culture.

Viewed from the perspective of cultural participation rather than marketing, videos are not 'messages', and neither are they 'products' that are distributed via social networks. Rather, they are the mediating mechanisms through which cultural practices are originated, adopted and (sometimes) retained within social networks. Indeed, scholars at the forefront of YouTube research argue that for those participants who actively contribute content and engage in cultural conversation around online video, YouTube is in itself a social network site; one in which videos (rather than 'friending') are the primary medium of social connection between 
participants. ${ }^{4}$ In considering what these new social dynamics of engagement with media might mean for thinking about cultural production and consumption, Henry Jenkins argues that value is primarily generated via 'spreadability'. Through reuse, reworking and redistribution, spreadable media content 'gains greater resonance in the culture, taking on new meanings, finding new audiences, attracting new markets, and generating new values.' 5 By this logic any particular video produces cultural value to the extent that it acts as a hub for further creative activity by a wide range of participants in this social network - that is, the extent to which it contributes to what Jonathan Zittrain might call YouTube's 'generative qualities'.6

There are of course very many videos on YouTube - in April 2008 there were over eighty million of them, and there will be millions more by the time this is published. ${ }^{7}$ They vary widely in the extent and qualities of their popularity, the media ecologies in which they originate and circulate, and the uses made of them by audiences. But it is the relatively small number of highly popular videos - those that sit at the 'fat head' of the 'long tail' - that are most useful in an attempt to rethink the dynamics of 'viral' video. Some of these videos do become extremely popular as one-offs, via wordof-mouth combined with media hype, on the basis of their novelty. Ostensibly user-created videos like Judson Laipply's 'Evolution of Dance' (viewed 85 million times as at May 2008) and Chris Crocker's 'Leave Britney Alone!' (viewed 20 million times), both picked up by the mainstream media only after they had achieved high levels of popularity on the web, are good examples. There are also many highly popular YouTube videos that were originally contributed by 'traditional media' companies like television networks and major music labels (especially Top 40 music videos - indeed, many of the most viewed and 'most favourited' videos of all time are official music videos). ${ }^{8}$ For my purposes, the more interesting examples of 'viral video', while being quantitatively popular in this way, also attract active, participatory and creative engagement from other participants. Among YouTube's 'greatest hits' are several good examples of how this works.

Burgess and Green's content survey of YouTube drew 
on a sample of 4,300 highly popular videos to compare user-created and traditional media content across four measures of popularity. ${ }^{9}$ From this data it is possible to distil a list of 'super popular top ten' videos with all-time views in the millions (even the tens of millions), and comments and video responses in the thousands. ${ }^{10}$ For the remainder of this chapter I concentrate on two of these highly popular videos, both of which illustrate the idea of viral video as participation in social networks particularly well. The first is the music video 'Chocolate Rain'. The second - another music video - is simply entitled 'Guitar'. ${ }^{11}$

The first thing to note is that neither of these videos are what we might understand to be 'traditional' media content - they were both coded in the study as 'user-created content' and they each draw on particular forms of vernacular creativity. ${ }^{12}$ Notably, like many of the most popular YouTube videos of all time both are performance-based and musicrelated, rather than narrative or information-based. ${ }^{13}$ But it isn't evident on the basis of a textual reading why-or, more importantly, in what ways - these videos were so popular during the period in which the study was conducted. It is only by looking at the creative activity that occurred around these videos that we can begin to understand just how important participation is to popularity.

Amateur singer-songwriter Tay Zonday's music video 'Chocolate Rain' had received more than twenty million views by April 2008. ${ }^{14}$ The video featured an apparently earnest Zonday (a University of Minnesota graduate student whose real name is Adam Bahner) singing his self-penned pop song into a vocal microphone against the backdrop of what appears to be a white sheet, with occasional cuts away to his hands on the keyboard. The video shows Zonday moving strangely to one side between lines - the on-screen titles explain: 'I move away from the mic to breathe in.'

The song has an extremely simple and repetitive melody and keyboard riff, drawing even more attention to Zonday's idiosyncratic vocal delivery; the low pitch of his voice, which has been compared to Paul Robeson and Barry White, is at odds with his boyish looks. The equally repetitive lyrics deal with themes of racial prejudice: 
Chocolate Rain

Raised your neighborhood insurance rates

Chocolate Rain

Makes us happy livin' in a gate

Chocolate Rain

Made me cross the street the other day

Chocolate Rain

Made you turn your head the other way

[Chorus]

Chocolate Rain

History quickly crashing through your veins

Chocolate Rain

Using you to fall back down again [Repeat]

It is arguably the combination of oddness and earnest amateurism that made 'Chocolate Rain' such a massive YouTube hit. According to Zonday himself, the initial spike of attention for the video (which occurred several months after it was first uploaded) originated 'as a joke at 4chan.org', a very popular image board and a significant source of internet 'memes'. ${ }^{15}$ It seems that 4 chan members swarmed YouTube to push 'Chocolate Rain' up the rankings initially motivated by the specific ethics of this internet subculture, oriented around absurdist and sometimes cruel frat-house humour. Calling to mind the Anonymous mantra 'REPRODUCE. REPRODUCE. REPRODUCE', it is easy to see how the 'viral' metaphor might apply to this piece of mischief making. ${ }^{16}$ And perhaps the joke was on the mischief-makers in the end, because all this activity created a celebrity out of Zonday. At the height of 'Chocolate Rain's popularity in the northern summer of 2007 , he appeared on a number of talk shows and was interviewed by the press, and eventually a self-parodying version of the song was produced for a faux-MTV film clip, which was used as part of a promotional campaign for Cherry Chocolate Diet Dr Pepper. ${ }^{17}$

But the uses of 'Chocolate Rain' as part of participatory culture ended up far exceeding the intentions of either the original producer or the original disseminators. There was a relatively brief but highly creative flurry of parodies, mash-ups and remixes as 'Chocolate Rain's popularity spiked. These derivative works reference ‘Chocolate Rain' by imitating or 
reusing parts of it and frequently combining them with many ideas from other sources, building on layers of knowledge built up in previous internet 'phenomena' as well as broadcast media fandom (like Star Wars).

One of the most popular parodies was a performance of the song by the lead character from the web sitcom 'Chad Vader, Dayshift Manager' (Darth Vader's 'less- talented, less-charismatic younger brother' and grocery store manager), which relies on YouTube for much of its audience. ${ }^{18}$ In a direct parody of the video, 'Chad Vader' uses the same mise-en-scene, melody and piano riff, and repeats the 'I move away from the microphone to breathe in' on-screen text, but substitutes lyrics that reference his own show, and audibly breathes through his Darth Vader mask in between lines, creating an additional layer of humour out of the 'breathing' joke. ${ }^{19}$ Another parody entitled 'Vanilla Snow' also emulates the visual and aural elements of the video (the sheet as backdrop, the overly contrastive lighting and yellow tones, the performer's pose in front of the microphone wearing headphones, the strangely deep voice and the backing track) but parodies the race politics of the song by substituting new lyrics that play on the metaphorical equation of 'chocolate' with racial blackness, riffing off 'vanilla' (whiteness) instead. ${ }^{20}$ Many of the YouTube spoofs and remixes are firmly embedded in online geek culture - examples include the '8bit remix', and especially the mash-up of the song's melody with the 'lyrics' from the 'All Your Base Are Belong To Us' meme, giving us the meme-uponmeme: 'All Your Chocolate Rain Are Belong To Us'. ${ }^{21}$

As this example shows, there is much more going on in viral video than 'information' about a video being communicated throughout a population. Successful 'viral' videos have textual hooks or key signifiers, which cannot be identified in advance (even, or especially, by their authors) but only after the fact, when they have become prominent via being selected a number of times for repetition. After becoming recognisable through this process of repetition, these key signifiers are then available for plugging into other forms, texts and intertexts - they become part of the available cultural repertoire of vernacular video. Because they produce new possibilities, even apparently pointless, nihilistic and playful forms of 
creativity are contributions to knowledge. This is true even if (as in the case of the 'Chocolate Rain' example) they work mostly to make a joke out of someone.

The video 'Guitar' is a more ordinary example, but one with far greater reach and staying power than the 'Chocolate Rain' phenomenon. 'Guitar' is a technically demanding neoclassical metal cover of Pachelbel's Canon in D, performed on electric guitar, in a bedroom. The performer in the video - seated on his bed, backlit by the sunlight streaming in from the window, his face obscured by a baseball cap - is a South Korean guitarist named Jeong-Hyun Lim. ${ }^{22}$ With over forty million views to date, his video is among the most popular YouTube videos of all time, and continues to attract new viewers, comments, and video responses.

But this video is not in any way original. Iteration and incremental innovation are historically fundamental to the evolution of musical technique and style, and the canon as musical form (in which layers of repetition are laid one above the other to create counterpoint) fundamentally invites imitation. Imitation is certainly the order of the day in this case: the piece that 'funtwo' (Lim) is performing, Canon Rock, is in turn a 'cover' of one of the most popular pieces of classical music ever written, and arranged for electric guitar and backing track by the Taiwanese musician and composer Jerry Chang (JerryC). The 'Canon Rock' arrangement became popular on the internet after a video of JerryC playing the piece was posted online. The backing track and guitar tabs were also made available, making it easy for other musicians to attempt to execute the arrangement, and to record their attempts as performances. The funtwo 'Guitar' video is one of these covers of Chang's arrangement, apparently originally uploaded to the Korean musician's website http://mule.co.kr. It was later uploaded to YouTube by a fan of Lim's, who posted it under the name 'funtwo'.23 Once it became popular on YouTube, the cycle of imitation, adaptation and innovation continued, and so on it went, ad infinitum.

Most of the response videos are either direct emulations (in which other bedroom guitarists test and prove their skills) or variations on the genre that the original 'Guitar' video distilled if not originated. In addition to the approximately 
one hundred direct video responses to the 'Guitar' video, a keyword search for 'canon rock' in YouTube returns more than thirteen thousand videos, most of which appear to be versions of the original 'Canon Rock' track, performed not only on guitars but also on pianos, violins and even a toy keyboard. ${ }^{24}$ These video responses frequently emulate the original miseen-scene-with the performer seated on a bed, backlit by light from a window, and looking down rather than at the camera. But there are a number of user-led innovations as well, most notably a proliferation of other arrangements of the original Canon by Pachelbel, performed on a staggering array of instruments, often using extended techniques and technologies like delay pedals. There is even a version of JerryC's original 'Canon Rock' available for the 'Frets on Fire' game (a free, open source clone of the popular title 'Guitar Hero', with a built in song importer/editor), enabling non-guitarists to emulate the virtuosity of the bedroom guitarists.

Perhaps the most interesting example is the montage video 'Ultimate Canon Rock', a remix of forty versions of the rock guitar arrangement, all performed by bedroom guitarists, and painstakingly edited together by YouTuber 'impeto' to make a complete new version of the performance. ${ }^{25}$ This video has received views in excess of three million, so that its popularity is beginning to approach that of the 'original' funtwo version. In itself, 'Ultimate Canon Rock' is an act of iterative vernacular creativity that has emerged out of the conversational dynamics of YouTube as a social network as much as out of any desire for self-expression. The video captures the ways in which small contributions from a large number of participants collectively add up to much more than the sum of their parts; the value of the video as an element in participatory culture cannot be attributed back to an original producer (because, for one thing, there isn't one).

The video is also a particularly good example of an existing performance genre, and one that is arguably paradigmatic of user-created content on YouTube - the virtuosic bedroom musical performance, straight to camera, vlog-style. The everydayness of the genre is all the more evident because it's situated in the bedroom - it draws on the long traditions of vernacular creativity articulated to 'privatised' media 
use. Productive play, media consumption and cultural performance have always been part of the repertoire of these privatised spaces of cultural participation, but increasingly they have become publicised via webcams, SNS profiles and YouTube itself. ${ }^{26}$

The personal musical performance as a YouTube genre operates as a site of both play and learning. It involves showing off - the showcasing of skill and the setting of standards for other players in the game to attain or beat; and it also operates as a site of peer learning and teaching - many of the descriptions and comments on covers of 'Canon Rock' ask for or offer critiques, tips and tricks, but in a generally supportive and often humorous manner. The bedroom music genre demonstrates how relatively simple uses of video technology (recording straight to camera and uploading without much editing) and highly constrained genres (the musical cover), while not necessarily contributing to the aesthetic 'advancement' of the medium, can invite further participation by establishing clear rules. The longevity of the video's popularity, I would argue, is a function of the extent to which the culture surrounding the neoclassical cover music video invites participation and rewards repetition and ongoing engagement.

In contrast, internet 'meme'-based viral videos rely on inside jokes that are spoiled by going mainstream, and therefore quickly reach a tipping point and tend to have relatively short shelf lives. A good example is the 'Rickrolling' phenomenon. Rickrolling - posting a misleading link that leads to Rick Astley's 1988 hit music video 'Never Gonna Give You Up', 'forcing' the unsuspecting viewer to sit through yet another viewing of the irritating one-hit wonder - gained particular prominence online and in the popular press throughout 2008. And it was widely reported by those in the know that once the Rickrolling meme had made the pages of the mainstream press, it was over. ${ }^{27}$

'Chocolate Rain' and 'Guitar' operate according to different temporal logics - or 'frequencies of public writing' - and they are structured by contrasting ethics of participation. ${ }^{28}$ But both examples show that in order to endow the metaphors implied by terms like 'memes', 'viruses' and 'spreadability' with any explanatory power, it is necessary to see videos as 
mediators of ideas that are taken up in practice within social networks, not as discrete texts that are produced in one place and then are later consumed somewhere else by isolated individuals or unwitting masses. These ideas are propagated by being taken up and used in new works, in new ways, and therefore are transformed on each iteration - a 'copy the instructions', rather than 'copy the product' model of replication and variation, and this process takes place within and with reference to particular social networks or subcultures. Further, and contra much of the hype about 'new media', many of the performative and communicative practices that spread via viral video 'crazes' are not at all new, but are deeply situated in everyday, even mundane, creative traditions.

Without stretching an overstretched metaphor too far, then, the dynamics of viral video could be understood as involving the spread of replicable ideas (expressed in performances and practices), via the processes of vernacular creativity, among communities connected through social networks. Rethinking 'viral video' in this way may contribute to a better understanding of how the cultures emerging around usercreated video-imitative, playful and often ordinary-are shaping the dynamics of contemporary popular culture.

\section{Notes}

1 See, for example A. Dobele, D. Toleman and M. Beverland, 'Controlled infection! Spreading the brand message through viral marketing', Business Horizons 48, no. 2 (2005).

2 R. Dawkins, The Selfish Gene (Oxford: Oxford University Press, 1976); and developed more fully by others, see for example S. Blackmore, The Meme Machine (Oxford: Oxford University Press, 1999).

3 D. Ackerman Greenberg, 'The secret strategies behind many viral videos', Techcrunch (November 2007): <http://www.techcrunch.com/2007/11/22/ the-secret-strategies-behind-many-viral-videos/>.

4 See especially P. G. Lange, 'Publicly private and privately public: Social networking on YouTube', Journal of Computer-Mediated Communication 13, no. 1 (2007): <http://jcmc.indiana.edu/vol13/issue1/lange.html>; and John C. Paolillo, 'Structure and network in the YouTube core', 41st Hawaii International Conference on System Sciences, 2008.

5 H. Jenkins, "'Slash me, mash me, spread me...”, Confessions of an Aca/Fan' (24 April 2007): <http://www.henryjenkins.org/2007/o4/ slash_me_mash_me_but_please_sp.html>.

6 J. Zittrain, The Future of the Internet-And How to Stop It (Yale: Yale University Press, 2008).

On 9 April 2008, a wildcard search returned 83.4 million videos. 
8 The most favourited YouTube videos are listed at <http://youtube.com/ browse? $\mathrm{s}=\mathrm{mf}>$.

9 This study was supported by the Convergence Culture Consortium and the Comparative Media Studies Program at MIT, and by the Centre of Excellence for Creative Industries and Innovation at Queensland University of Technology. See J. Burgess and J. Green, YouTube: Online Video and Participatory Culture (Cambridge: Polity Press, 2008).

10 Popularity was measured by the total number of views the videos had received at the time of data capture.

11 'Guitar' was the video with the most views overall in the entire sample for the period, and it appeared in the 'most discussed' and 'most responded' lists, not only the 'most viewed' list.

12 Videos that appeared to have been produced outside of the media industries and related professions.

13 A quick scan of the most viewed videos of all time at <http://youtube.com/ browse $\mathrm{s}=\mathrm{mp} \& \mathrm{t}=\mathrm{a} \& \mathrm{c}=\mathrm{O} \& \mathrm{l}=\& \mathrm{~b}=\mathrm{O}>$ confirms this; the page is dominated by music videos.

14 See <http://www.youtube.com/watch?v=EwTZ2xpQwpA>.

15 'Chocolate Rain', Wikipedia: <http://en.wikipedia.org/wiki/Chocolate_Rain $>$.

16 See <http://www.wikichan.org/index.php/Anonymous $>$.

17 See 'Cherry Chocolate Rain' <http://youtube.com/watch?v=2x2W12A8Qow>.

18 Chad Vader, which focuses on Star Wars parody and other geek humour, is a creation of Blame Society Productions (Aaron Yonda and Matt Sloan). See $<$ http://www.blamesociety.net/>.

19 See $<$ http://www.youtube.com/watch?v=P6dUCOS1bMo $>$.

20 See $<$ http://www.youtube.com/watch?v=nTQOpibv_OA $>$.

21 See $<$ http://www.youtube.com/watch?v=caIBKOztlAo $>$; $<$ http://www.youtube. com/watch? $=$ dUyxurUWtSQ $>$.

22 After several impostors came forward claiming to be funtwo, Lim was revealed as the real 'performer in the "Guitar" video' in a New York Times article. Virginia Heffernand, 'Web guitar wizard revealed at last', New York Times, 27 August 2006, see $<$ http://www.nytimes.com/2006/o8/27/arts/television/27heff.htm>.

23 See Lim's Wikipedia entry: <http://en.wikipedia.org/wiki/Jeong-Hyun_Lim >.

24 See $<$ http://youtube.com/watch?v=6Xvd_62Oec8 $>$.

25 See $<$ http://youtube-impeto.blogspot.com/ $>$.

26 S. L. Baker, 'Pop in(to) the bedroom: Popular music in pre-teen girls' bedroom culture', European Journal of Cultural Studies 7, no. 1 (2004): 75-93.

27 See 'The biggest little internet hoax on wheels hits mainstream', Fox News, 22 April $2008<$ http://www.foxnews.com/story/o,2933,352010,oo.html>.

28 J. Hartley, Television Truths (London: Blackwell, 2008), 30-6. 